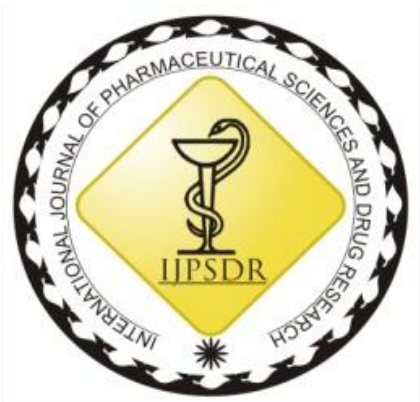

ISSN: 0975-248X

RESEARCH ARTICLE CODEN (USA): IJPSPP

$(\mathrm{cc})$ EY-NC-SA

\title{
Ocular Tolerability and Efficacy of Ebastine Colloidal Formulation in Allergic Conjunctivitis
}

\author{
J Mehetre ${ }^{*}$, V Kumar'1, T Mehta², M Gohel ${ }^{3}$, N Surti ${ }^{4}$ \\ ${ }^{1}$ ITM School of Pharmacy, Gujarat Technological University, Gujarat, India \\ ${ }^{2}$ Institute of Pharmacy, Nirma University, Gujarat, India \\ ${ }^{3}$ Anand Pharmacy College, Gujarat Technological University, Gujarat, India \\ ${ }^{4}$ Babaria Institute of Pharmacy, Gujarat Technological University, Gujarat, India
}

Copyright (C) 2019 J Mehetre et al. This is an open access article distributed under the terms of the Creative Commons AttributionNonCommercial-ShareAlike 4.0 International License which allows others to remix, tweak, and build upon the work non-commercially, as long as the author is credited and the new creations are licensed under the identical terms.

\begin{abstract}
Allergic conjunctivitis (AC), defined by ocular itching, hyperemia, lacrimation and edema, impairs the quality of life across the globe. Ebastine is available as an oral antihistamine formula, such as tablets and syrup, for allergic disorders. Topical antihistamines are preferred over oral agents since their direct application at the site of action results in rapid onset and superior efficacy with less systemic side effects. The objective of the present work was to evaluate the antiallergic potential of optimized ebastine $(1 \% \mathrm{w} / \mathrm{v})$ colloidal ocular formulation by performing in vitro study like hen's egg chorioallantoic membrane test (HET-CAM) for tolerability and in vivo efficacy study in ovalbumin (OA)-induced allergic conjunctivitis (AC) with acute ocular irritation study. Eye scratching behavior and edema were evaluated after topical antigen challenge. Edema was scored at periodic interval after the instillation of ovalbumin followed by histopathology. The results showed that ebastine $(1 \% \mathrm{w} / \mathrm{v})$ colloidal ocular formulation was effective in inhibiting symptoms of eye inflammation induced by ovalbumin. Further, the study indicated that said formulation has a quick onset and the duration of effect sufficient to provide relief from symptoms for $24 \mathrm{hr}$. Ocular irritation by HET-CAM assay showed that the developed formulation does not cause any irritation to the blood vessels. Acute ocular irritation test was performed using rabbits and results showed that developed formulation was non-irritant to the eye. The present study revealed that the ocular ebastine formulation could offer a novel therapeutic opportunity against IgE-mediated allergic conjunctivitis.
\end{abstract}

Keywords: Allergic Conjunctivitis, Colloidal Formulation, Ovalbumin, Chorioallantoic Membrane.

DOI: 10.25004/IJPSDR.2019.110405

Int. J. Pharm. Sci. Drug Res. 2019; 11(4): 129-136

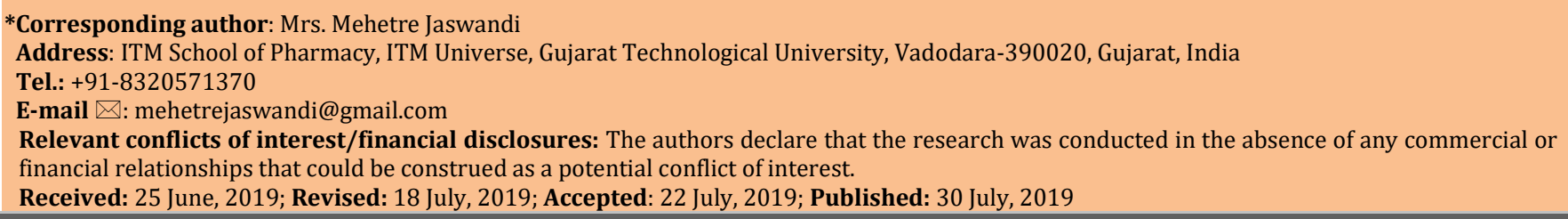

\section{INTRODUCTION}

Allergic conjunctivitis is most common immunemediated diseases of the eye, clinically characterized by ocular itching, redness, lacrimation, edema and presence of inflammatory cells specifically eosinophil's in the conjunctiva. [1-2] The incidence of allergic conjunctivitis has already increased dramatically over the past years. The diseases are often concomitant with 
other allergic diseases such as allergic rhinitis, atopic dermatitis and allergic asthma. ${ }^{[3]}$ Allergic conjunctivitis categorized into acute and late phase disease. The acute phase is described clinically by ocular itching, hyperemia, and edema, supported by cellular infiltration into the conjunctiva. The late phase reaction is activated by immunoglobulins and characterized by the presence of inflammatory squeal and clinical symptoms after the acute phase. ${ }^{[4]}$ Histamine is the dominant allergic reaction mediator. [5-6] Histamine H1 receptor antagonists are the prime class of medication in the therapy of allergic and non-allergic conjunctivitis. For eye application, topical antihistamines are preferred over oral agents since their direct application at the site of action results in rapid onset and superior efficacy caused by high local concentrations achieved after their instillation into the eye. The topical application also minimizes the risk of systemic side effects. ${ }^{7-8]}$

The test formulation used in the present study was laboratory made surfactant-based ocular ebastine colloidal formulation. Ebastine is the second-generation $\mathrm{H} 1$ receptor an antagonist, chemically 1-[4-(1, 1dimethyl ethyl) phenyl]-4-[4-(diphenyl methoxy) piperidin-1-yl] butan-1-one indicated by oral route for various allergic manifestations of skin, nasal and ocular site. ${ }^{[1-2]}$ Ebastine $(1 \% \mathrm{w} / \mathrm{v})$ oil in water microemulsion formulation was formulated by phase titration method using D-optimal mixture design, with the goal of enhancing solubility, thereby enhancing bioavailability due to site specificity as well as reducing systemic side effects and improving patient compliance.

Campul MCM EP selected as the oil phase. The blend of Labrasol with Tween 80 and blend of Propylene glycol with glycerol were selected as surfactant and co surfactant, respectively. A main challenge in developing a sterile ophthalmic formulation is the capacity to guarantee that the formulation has acceptable $\mathrm{pH}$, clarity, zeta potential, globule size, osmolarity, surface tension, viscosity etc. Resultant developed formulation showed droplet size $(142 \pm 0.16$ $\mathrm{nm})$, polydispersity index (below 1), refractive index $(1.369 \pm 0.04)$ and osmolarity $(291 \pm 0.301 \mathrm{mOsm} / \mathrm{L})$. The $\mathrm{pH}$ value of the developed formulation was $6.9 \pm$ 0.12 , which can be easily buffered by tear fluid ( $\mathrm{pH}$ 7.27.4). Low microemulsion surface tension ensures good spreading effect on ocular surface and mixing with precorneal film components, thereby improving contact with ocular surface. The surface tension of the developed formulation was found to be $34.75 \pm 0.13$ $\mathrm{mN} / \mathrm{m}$. Zeta potential and viscosity of developed formulations was found to be $-22.6 \pm 0.39 \mathrm{mV}$ and 13.19 $\pm 0.121 \mathrm{cps}$ respectively. These determined optimum physicochemical properties were observed to be eyefitting, which is published in our previous paper. ${ }^{[9]} \mathrm{In}$ vitro results suggest that the developed formulation is suitable for further investigation in animal models to elucidate the safety and efficacy in treatment of allergic conjunctivitis. Hence, the present study was planned for determination of tolerability and assessment of efficacy of previously developed ebastine $(1 \% \mathrm{w} / \mathrm{v})$ colloidal ocular formulation for its onset and duration of effect in ovalbumin-induced conjunctivitis models in guinea pig.

\section{MATERIALS AND METHODS}

\section{Animals}

New Zealand white rabbits approximate weighing 1.5$2 \mathrm{~kg}$ was used for studying acute ocular irritation symptoms like blinking, redness, lacrimation etc. Dunkin-Hartley guinea pigs approximate weighing 300-350 g was used for studying efficacy study by ovalbumin-induced conjunctivitis model and scratching behavior. Rabbits were housed as one animal per cage while guinea pigs were housed as 3-4 animals per cage (polypropylene cage of $421 \times 290 \times$ $190 \mathrm{~mm}$ ) and both maintained at $20-30^{\circ} \mathrm{C}$ and $50-55 \%$ relative humidity in a natural light and dark cycle of 12 $\mathrm{h} / 12 \mathrm{~h}$. They were allowed free access to certified pelleted food (Harlan, USA) and potable water in water bottles. The animals were acclimatized to animal holding laboratory area for 7 days prior to experiments. The experimental protocol was approved by the Institutional Animal Ethics Committee (IAEC) Reference No. 984/01/2017-07 for the use of animal in the study. Utmost care was taken to ensure that animals were treated in the most human and ethically acceptable manner. Fertilized Chick Eggs for Chorioallantoic membrane assay was obtained from Government Poultry House, Vadodara. Reagents like Isopropyl alcohol $(70 \%)$, Normal saline $(0.9 \%$ sodium chloride) and $1 \mathrm{~N} \mathrm{NaOH}$ used in experiment are of analytical grade.

\section{Drug}

Laboratory made ebastine $(1 \% \mathrm{w} / \mathrm{v})$ colloidal ocular formulation

Ocular Irritation Study by Hen's Egg Test Chorioallantoic Membrane (HET-CAM)

\section{Testing protocol for CAM Test}

\section{Selection of Eggs}

The eggs were collected less than 1 week after lying and incubated for about 9 days; on $10^{\text {th }}$ day, their blunt ends are tested by the candling lamp. Only the eggs with emergent vascular system were selected for the test.

\section{Preparation of the Eggs for Test}

Candling procedure helps in identifying the air space and it was marked on the eggs; then, after wiping with $70 \%$ IPA and a small window was made on the shell at the pointed end of the egg. The shells of the egg are opened at that marked portion on the blunt ends. The underlying membrane was carefully removed in such a way that underlying blood vessels are not damaged. Exposed chorioallantoic membrane (CAM) was treated with 10 microliter of the test formulation. The chorioallantoic membrane was also treated with 10 microliter of $1 \mathrm{~N} \mathrm{NaOH}$ and considered as positive 
control and 10 microliter of $0.9 \% \mathrm{w} / \mathrm{v} \mathrm{NaCl}$ as negative control. The effects were observed near the surroundings of the applied sample within $5 \mathrm{~min}$. After $5 \mathrm{~min}$, change in CAM was observed for parameters like hemorrhage, coagulation and lysis. [10-12]

\section{Ocular Tolerability Test}

Blinking Index

\section{Testing Protocol for Blinking Index (B.I.)}

The animals were held on top of a lab table with a thick absorbent paper covered by hand. Blinking counts were performed with an electronic count-up timer over a 5minute period. Using an adjustable volume digital pipette, saline and test formulation were applied to the lower cul-de-sac while pulling the upper eyelid gently and tilting the head of the animal slightly, making sure that the formulation did not spill out before the first blink. A volume of 25 microliters was used here as a substantial stimulus for blinking was found in preliminary tests. The right and left eyes were tested with saline, and the test solution was tested 30-60 minutes later. [13]

\section{Mathematical Expression}

The ratio between the number of blinks, counted over a 5-minute period following the instillation of a test solution, and the corresponding number of blinks, counted over a 5-minute period, in the same animal following the instillation of a normal saline solution, gives the Blinking Index (B.I.)

The average result obtained consecutively from both eyes of the same animal was entered as a single value. The results are presented as Mean \pm Standard Error of the Mean (S.E.M.).

\section{Acute Ocular Irritation Study}

The animals were held in position same as that of previously mention in 2.2.1. The saline and test formulation were applied to the lower cul-de-sac while pulling the upper eyelid gently and the animals were observed up to $60 \mathrm{~min}$ for redness, swelling, watering of the eye. [14]

Ocular Efficacy Study

Ovalbumin-Induced Allergic Conjunctivitis

Testing Protocol for Ovalbumin-Induced Allergic Conjunctivitis

Allergic conjunctivitis was induced as per previously reported protocol. [15-17] Briefly, animals were sensitized on day $1,7,14$, and 21 by intraperitoneal injection of ovalbumin $(100 \mu \mathrm{g} / 0.5 \mathrm{ml} / \mathrm{animal})$, suspended in aluminium hydroxide gel as an adjuvant. Nonsensitized animals used for the experiment received only aluminium hydroxide gel. Seven days after the last sensitization, animals were used for the experiments assessing efficacy of test formulation.
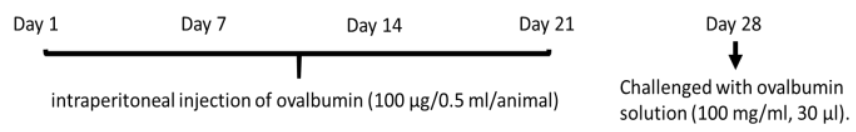

At the time of experiment, a $20 \mu \mathrm{l}$ test formulation, saline, was instilled into the right eye of respective group using a micropipette and for oral, ebastine (3 $\mathrm{mg} / \mathrm{kg}$ ) in $0.5 \%$ CMC. At 0.5 and $24 \mathrm{~h}$ after the instillations, the eye was challenged with ovalbumin solution $(100 \mathrm{mg} / \mathrm{ml}, 30 \mu \mathrm{l})$. Edema was scored at 15, 30, 60,90 , and $120 \mathrm{~min}$ after the instillation of ovalbumin. For evaluation of edema, scoring system was used.

Scratching Behavior

Eye scratching behavior was defined as fore-limb movements over two times directed to the ocular surface. [18] In the same sensitization protocol as describe in 2.3.1. Along with edema, the number of eye scratches was counted for $30 \mathrm{~min}$. The scratching response was assessed after topical antigen challenge at 0.5 h. ${ }^{[19]}$

\section{Histopathological Study}

The eyeballs together with the conjunctiva and lids of animals from the saline, saline + ovalbumin and test formulation group were exenterated and fixed in $10 \%$ buffered formalin. Tissues were subsequently processed for dehydration in a series of ascending alcohol concentrations. The samples embedded into paraffin wax and stained with hematoxylin and eosin. [20-29] DPX was used as mounting medium and micro toming was performed using microtome (model 0126, Yorco, India). The histopathological examinations for determination of damage/irritation due to the formulation were performed using inverted microscope (Nikon TS-100).

\section{RESULTS AND DISCUSSION}

Ocular Irritation Study by Hen's Egg Test Chorioallantoic Membrane (HET-CAM)

HETCAM (Hen's chorioallantoic membrane) experiment was used for testing the potential of optimized formulation for eye irritation. The effects of test formulation as well as positive and negative controls on the chorioallantoic membrane were noted before and after the treatment as shown in Fig. 1. There was a remarkable difference between the test formulation and positive control by observing the changes in the chorioallantoic membrane. The positive control $(0.1 \mathrm{~N} \mathrm{NaOH})$ induced major damage to the CAM. The $0.1 \mathrm{~N} \mathrm{NaOH}$ causes hemorrhage followed by the lysis of blood vessels, whereas test formulation and negative control $(0.9 \% \mathrm{NaCl})$ does not show severe changes in the chorioallantoic membrane after the application. The severity of ocular irritation of the formulations was compared with that of positive and negative controls. The images showed that there was no considerable change in the blood vessel morphology of isolated CAM and formulation did not cause any damage or irritation to the eye upon application.

\section{Blinking Index}

The B.I. is defined as the ratio of the number of blinks (drug) divided by the number of blinks (saline) and it is used as an indication of the drug irritability. As shown in Table 1, the blinking index of saline solution and test formulation is $1.5 \pm 0.4$ and $2.4 \pm 0.6$ respectively. After topical application the strong correlation between the osmolarity of the solution and the irritation/pain 
J Mehetre et al. / Ocular Tolerability and Efficacy of Ebastine Colloidal Formulation in Allergic...........

discomfort was observed. Obviously, other factors such as $\mathrm{pH}$, the presence of other chemicals (i.e. preservatives) and the drug's own chemical nature can greatly affect its potential for eye discomfort/irritation.

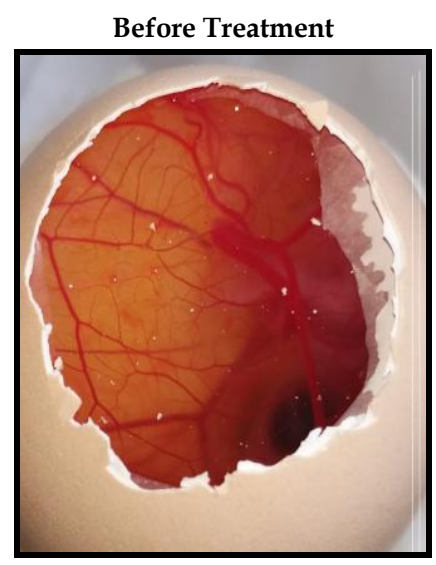

a. Test Formulation

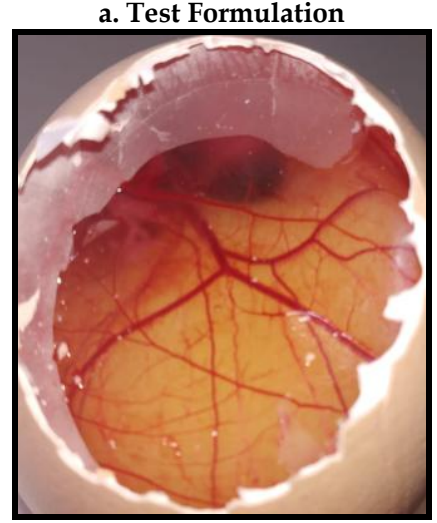

b. Positive Control ( $0.9 \% \mathrm{NaCl})$

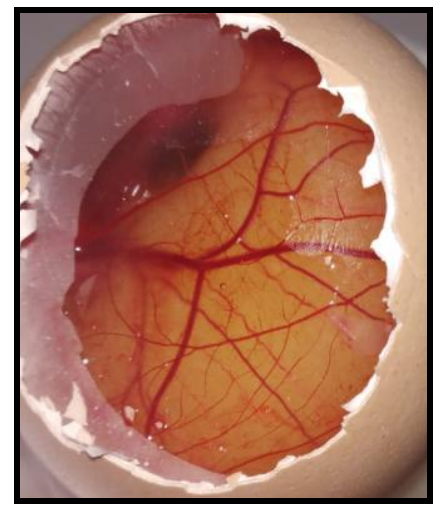

c. Negative Control $(0.9 \% \mathrm{NaCl})$
5 min After Treatment

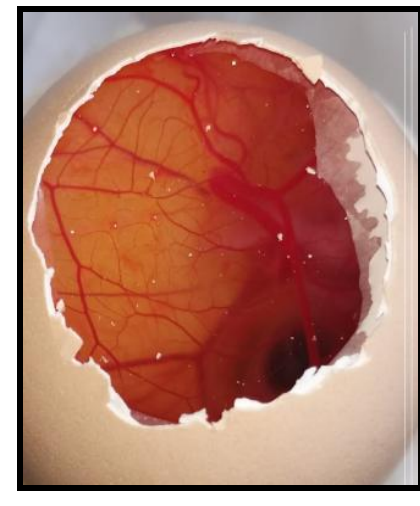

a. Test Formulation

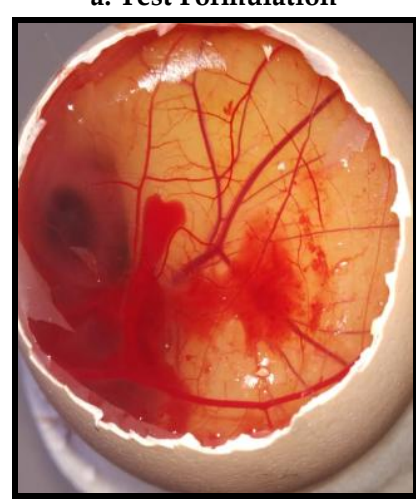

b. Positive Control $(0.9 \% \mathrm{NaCl})$

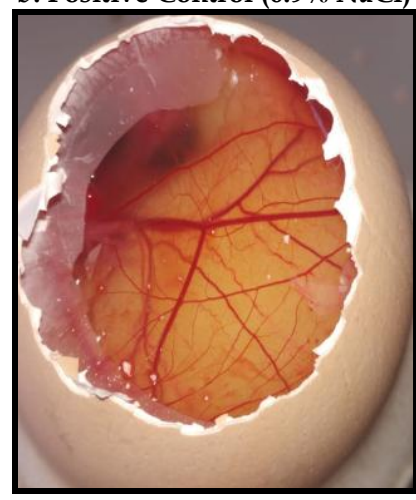

c. Negative Control $(0.9 \%$ $\mathrm{NaCl})$

Fig. 1: Ocular Irritation Study by Chorioallantoic Membrane Assay a. CAM treated with Test formulation b. CAM treated with positive control $(0.1 \mathrm{~N} \mathrm{NaOH})$ c. CAM treated with Negative control $(0.9 \%$ $\mathrm{NaCl})$; Test formulation: Ebastine $(1 \% \mathrm{w} / \mathrm{v})$ ocular formulation

Table 1: Blinking Index and Clinical Symptoms

\begin{tabular}{ccccc}
\hline & Blinking & \multicolumn{3}{c}{ Observation } \\
\cline { 3 - 5 } Treatment & $\begin{array}{c}\text { Index } \\
\text { (Mean } \pm \\
\text { SEM) }\end{array}$ & $\begin{array}{c}\text { Eye } \\
\text { Closure } \\
\text { (swelling) }\end{array}$ & Lacrimation & Redness \\
\hline $\begin{array}{c}\text { Saline } \\
\text { Test }\end{array}$ & $1.5 \pm 0.4$ & $0 / 4$ & $1 / 4$ & $0 / 4$ \\
formulation & $2.4 \pm 0.6$ & $0 / 4$ & $2 / 4$ & $1 / 4$ \\
\hline
\end{tabular}

$(\mathrm{n}=4 /$ treatment); Test formulation: Ebastine $(1 \% \mathrm{w} / \mathrm{v})$ ocular formulation

Table 2: Edema Score (At $0.5 \mathrm{~h}$ and $24 \mathrm{~h}$ after Topical Antigen Challenge)

\begin{tabular}{|c|c|c|c|}
\hline \multirow[t]{2}{*}{ Group } & \multirow[t]{2}{*}{ Treatment } & \multicolumn{2}{|c|}{$\begin{array}{c}\text { Sum of edema score } \\
(\text { Mean } \pm \text { SEM) }\end{array}$} \\
\hline & & $0.5 \mathrm{~h}$ & $24 \mathrm{~h}$ \\
\hline $\begin{array}{c}\text { Non } \\
\text { sensitized }\end{array}$ & Saline + ovalbumin & $0.00 \pm 0.00$ & $0.00 \pm 0.00$ \\
\hline Sensitized & Saline + ovalbumin & $17.66 \pm 0.56$ & $16.39 \pm 0.02$ \\
\hline Sensitized & $\begin{array}{l}\text { Ebastine }(1 \% \mathrm{w} / \mathrm{v}) \text { ocular } \\
\text { formulation }+ \text { ovalbumin }\end{array}$ & $3.56 \pm 0.02 *$ & $9.43 \pm 0.14^{*}$ \\
\hline Sensitized & $\begin{array}{c}\text { Ebastine ( } 3 \mathrm{mg} / \mathrm{kg} \text { ) } \\
\text { suspension in } 0.5 \% \mathrm{CMC} \\
\text { oral + ovalbumin }\end{array}$ & $11.53 \pm 0.16^{*}$ & $14.48 \pm 0.14$ \\
\hline
\end{tabular}

"Significant compared to saline + ovalbumin treated sensitized animals, ANOVA followed by Dunett's test, $p<0.05$. Each value represents mean \pm SEM of 4 animals / treatment

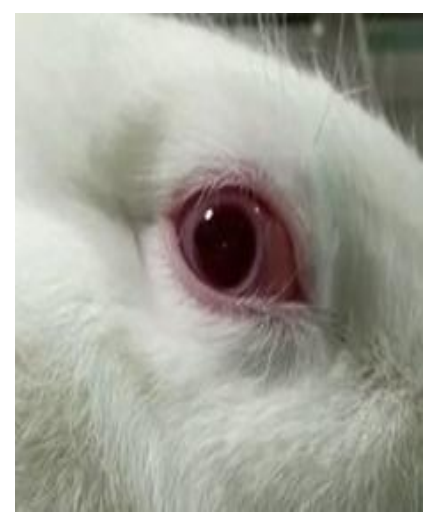

Saline after $60 \mathrm{~min}$

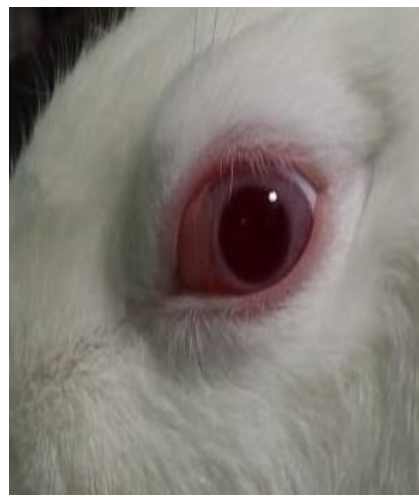

Test formulation after $60 \mathrm{~min}$ Fig. 2: Acute Ocular Irritation Study; Test formulation: Ebastine (1\% w/v) ocular formulation

\section{Acute Ocular Irritation Study}

Comparable scoring in symptoms like eye closure, lacrimation and redness with respect to saline in rabbits indicates that the test formulation was well tolerated by the rabbits causing less discomfort. Thus the test formulation was found to be nonirritating with no ocular damage or abnormal clinical signs to the cornea, iris or conjunctivae observed. Hence the test formulation was suitable for the eye instillation and viable alternative to conventional ocular formulation (Fig. 2 and Table 1).

\section{Ovalbumin-Induced Allergic Conjunctivitis}

At 0.5 and $24 \mathrm{~h}$ after the instillations, the eye was challenged with ovalbumin solution $(100 \mathrm{mg} / \mathrm{ml}, 30 \mu \mathrm{l})$. Edema was scored at 15, 30, 60, 90, and 120 min after the instillation of ovalbumin. (Table 2) The edema scoring was done according to graded scale. Following system was used for assigning the edema scores

0 -No edema

1-Slight edema

2-Partial eversion of eye

3-Eyelid half-closed

4-Eye swelling, more than half eyelid closed

The observations which did not match exactly with the score mentioned in the following scoring system were assigned a value between two adjacent scores up to 0.5 . E.g. for scoring eyelid edema a value of 1.5 was assigned in case of the score falling between 1 and 2 . 


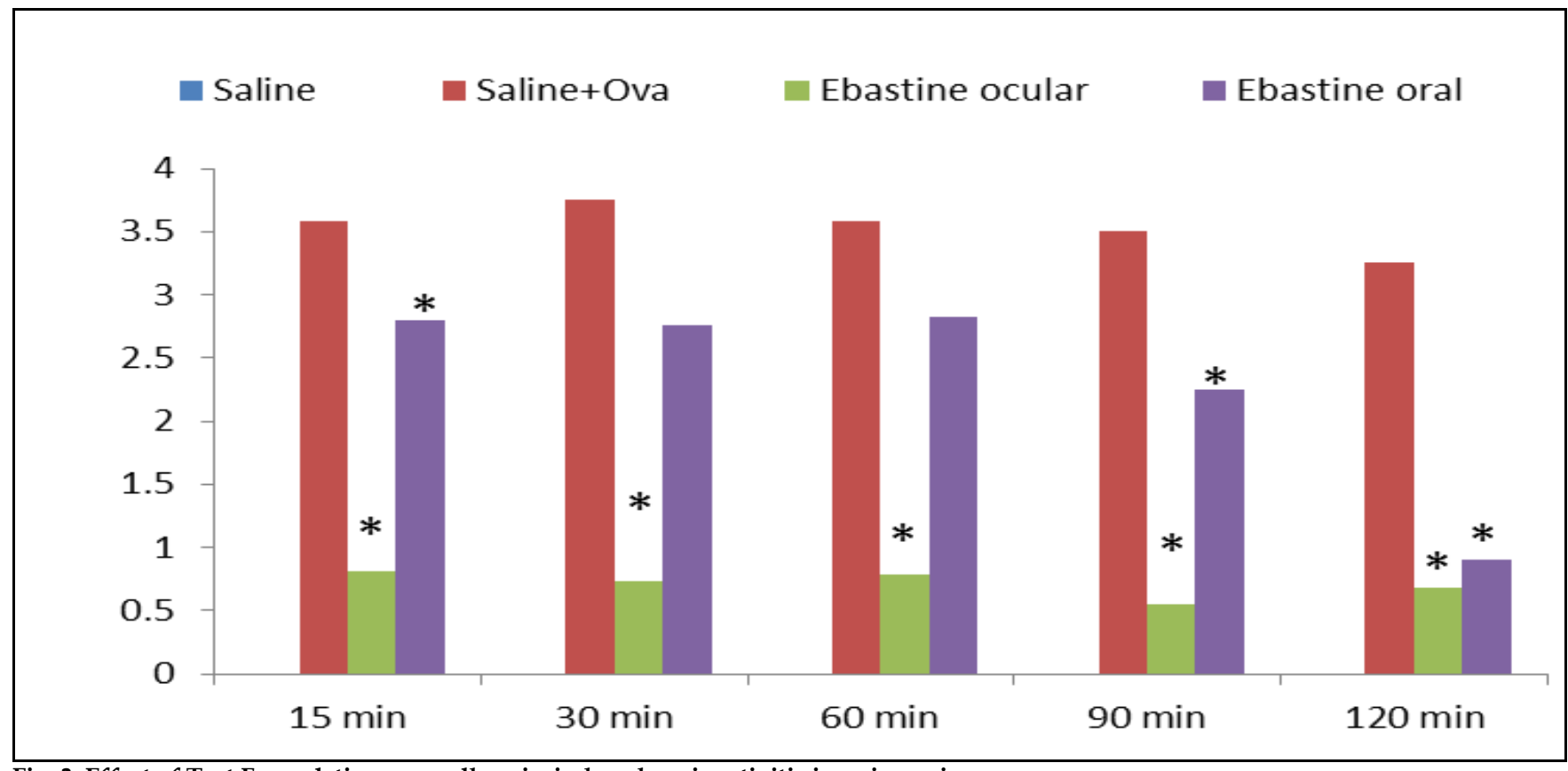

Fig. 3: Effect of Test Formulation on ovalbumin-induced conjunctivitis in guinea pigs

Onset of effect- Time point: $0.5 \mathrm{~h}$; ${ }^{*}$ Significant compared to saline + Ovalbumin treated animals, ANOVA followed by Dunett's test, $p<0.05$ Each value represents mean \pm SEM.

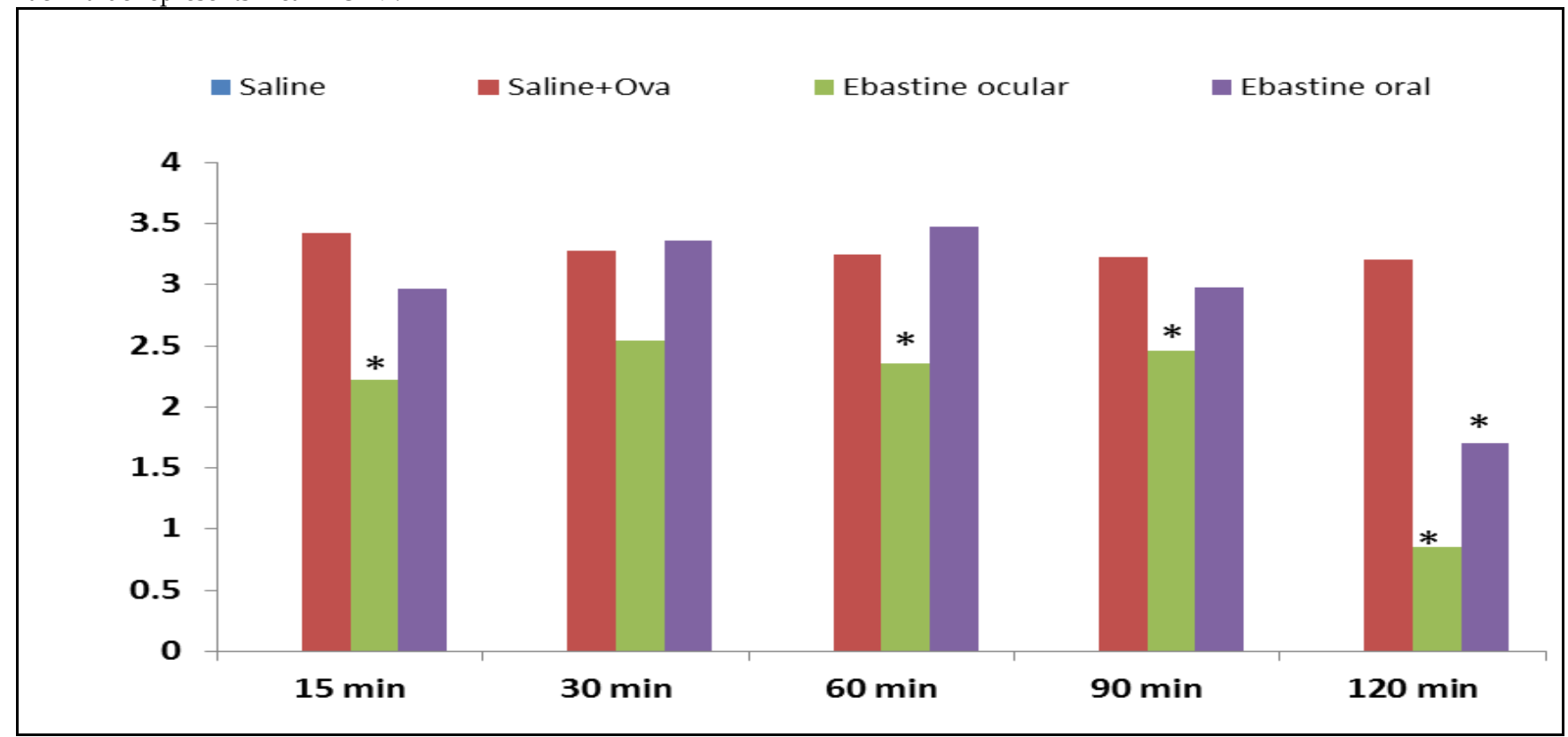

Fig. 4: Effect of Test Formulation on ovalbumin-induced conjunctivitis in guinea pigs

Duration of effect- Time point: $24 \mathrm{~h}$, *Significant compared to saline + Ovalbumin treated animals, ANOVA followed by Dunett's test, $p<0.05$ Each value represents mean \pm SEM.

The Fig. 3 and Fig. 4 indicate graphical presentation of scoring at 15, 30, 60, 90, and $120 \mathrm{~min}$ after topical antigen challenge at $0.5 \mathrm{~h}$ and $24 \mathrm{~h}$. Guinea pigs in the OA induced AC model observed for clinical symptoms as shown in Fig. 5. The results presented in Table 2 indicate that the test formulation (ebastine $1 \% \mathrm{w} / \mathrm{v}$ ocular) instilled $0.5 \mathrm{~h}$ and $24 \mathrm{~h}$ before the ovalbumin challenge caused significant inhibition of conjunctivitis symptoms. While the oral ebastine caused significant inhibition of conjunctivitis symptoms at $0.5 \mathrm{~h}$ only. It was also observed that compared to Ova challenge, test formulation showed $79.84 \%$ inhibition at $0.5 \mathrm{~h}$, the effect persist up to $24 \mathrm{~h}$ with $42.46 \%$ inhibition while oral ebastine showed $34.71 \%$ inhibition at $0.5 \mathrm{~h}$. This result indicates that topical formulation of ebastine showed better efficacy in ova induce conjunctivitis model at very low dose as compared to oral.

\section{Scratching Behavior}

After the instillation of $30 \mu \mathrm{l} /$ site of ovalbumin dissolved in normal saline solution $(0.9 \% \mathrm{NaCl})$ into the eye, guinea pigs were placed into the observation cage (1 animal/cage), and the number of eye scratches was counted for $30 \mathrm{~min}$. The scratching response was assessed after topical antigen challenge at $0.5 \mathrm{~h}$. Animals treated with topical ebastine showed a significant reduction in itch-scratch response as compared to ova challenge and oral ebastine (Fig. 6). 


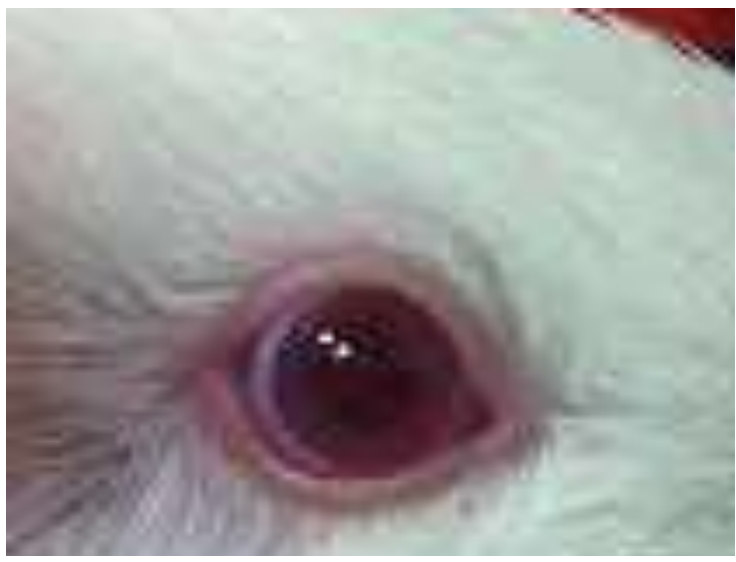

A

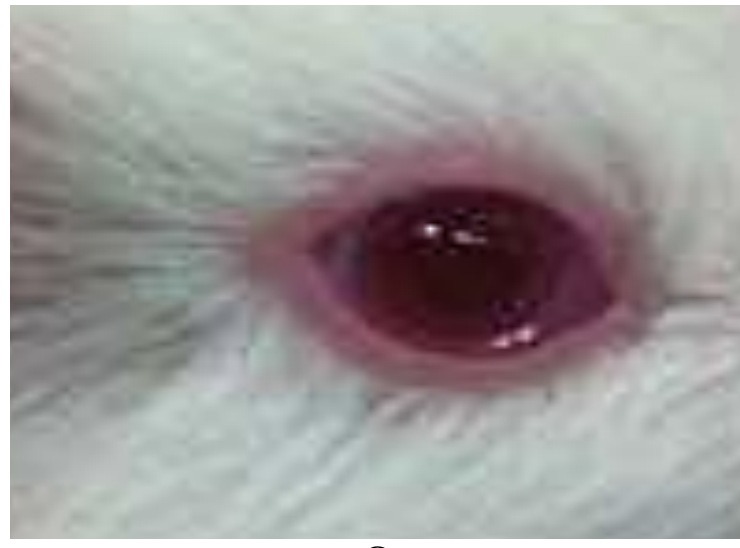

C

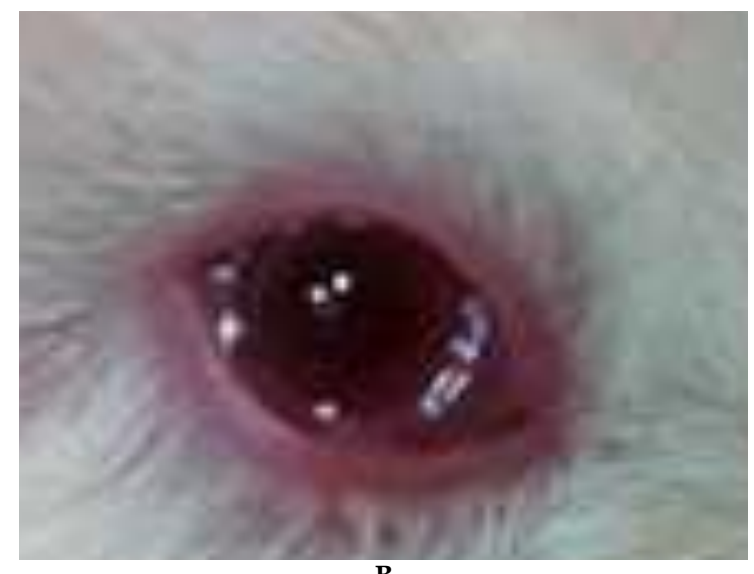

B

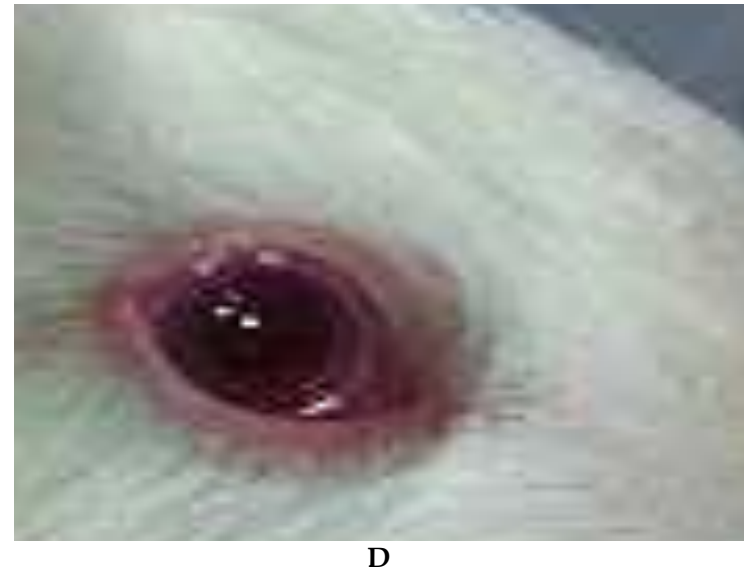

Fig. 5: Instillation of ovalbumin in non sensitized animal do not induce edema, hence no eyelid swelling (A). Severe edema, redness, and lacrimation were observed in sensitized animal after ovalbumin challenge (B). Ebastine $(1 \% \mathrm{w} / \mathrm{v})$ ocular formulation + ovalbumin $(\mathrm{C})$. Ebastine $(3 \mathrm{mg} / \mathrm{kg})$ suspension oral + ovalbumin (D).

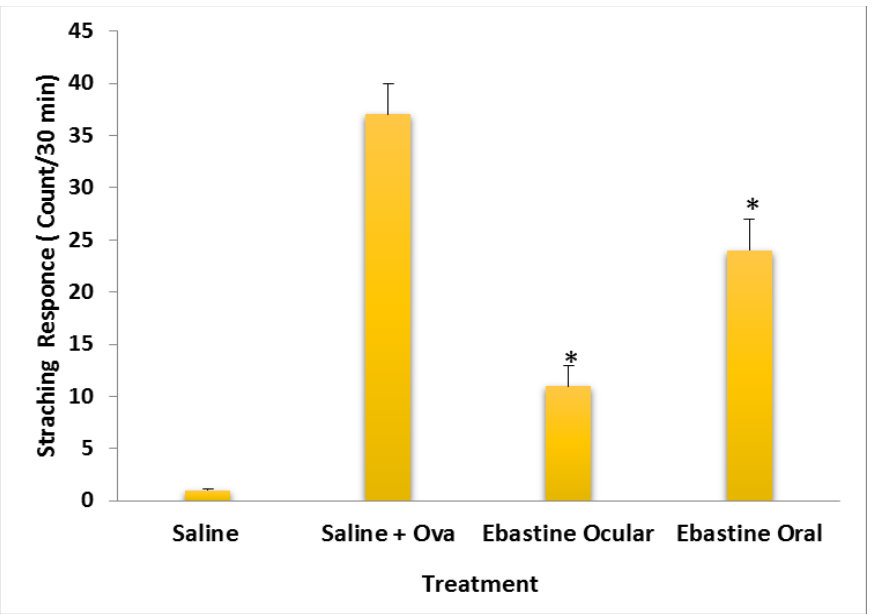

Fig. 6: Scratching Response

*Significant compared to saline + Ovalbumin treated animals ANOVA followed by Dunett's test, $p<0.05$. Each value represents mean \pm SEM.

\section{Histopathological Study}

Histopathological conditions of conjunctiva after treatment with saline (negative control), saline+ ovalbumin (positive control), and test formulation (ebastine $1 \% \mathrm{w} / \mathrm{v}$ ocular) are shown in Fig. 7. No significant damage/harmful or mild epithelium damage effects on the microscopic structure of the conjunctiva treated with test formulation was observed in comparison to that of sample treated with topical allergen ovalbumin indicating the safety of the test formulation for ocular application. Conjunctiva treated with topical allergen showed severe damage epithelium cellular layer and edema, as well as neutrophil and eosinophil infiltration.

\section{Data Analysis}

Data obtained in different groups expressed as mean \pm Standard error of mean (SEM) were analyzed using one-way ANOVA followed by Dunett's test. Statistical significance was considered as $p$ value $<0.05$. Statistical analysis was performed using the Sigma Stat, Version 3.1. (SPSS Inc., USA)

Allergic conjunctivitis is a type- 1 hypersensitivity reaction resulting from the cascade of events initiated by allergen crosslinking of IgE molecules on mast cells in the conjunctiva. Ocular irritation is a prevalent adverse effect when new ocular formulations are developed.

To conclude, our previously developed ebastine (1\% $\mathrm{w} / \mathrm{v}$ ) colloidal ocular formulation proved its tolerability in in vitro HET-CAM assay by preserving normal architecture of blood vessels and in vivo acute irritation study evident by reduced lacrimation, blinking index and redness. Further, the present study revealed the therapeutic role of formulation in allergic conjunctivitis by exhibiting statistically significant reduction in conjunctivitis symptoms like edema and scratching as compared to oral ebastine. In histopathological evaluation, ocular formulation caused 
mild epithelium damage with less eosinophil infiltration than in conjunctiva treated with ovalbumin alone.

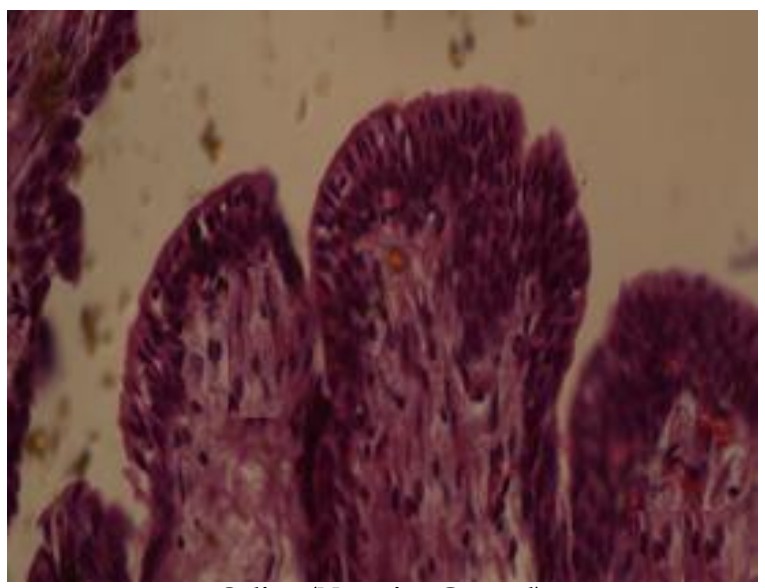

Saline (Negative Control)

Normal epithelium cell layer and no edema, as well as neutrophil and eosinophil exudations in the proper lamina (40x)

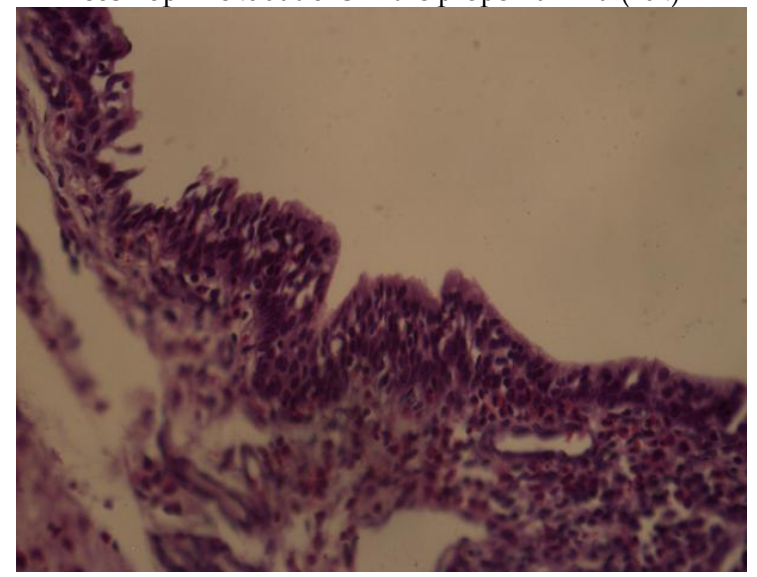

Saline + Ovalbumin (positive control)

Damage epithelium cellular layer and edema, as well as neutrophil and eosinophil infiltration (40x)

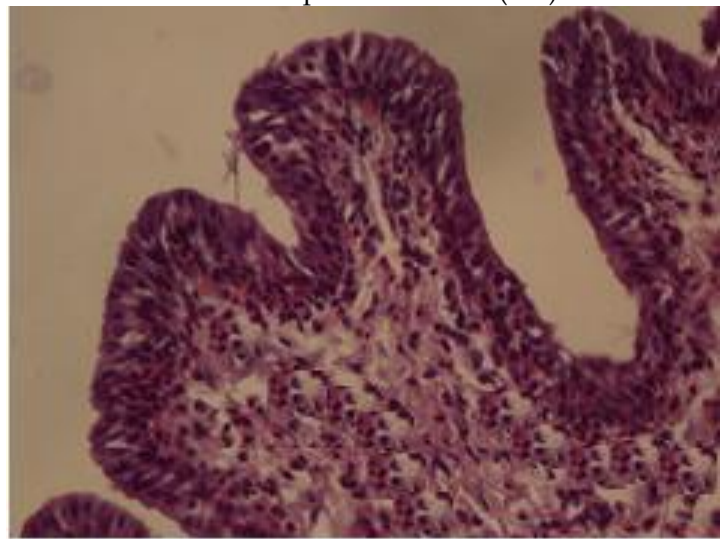

Test formulation (Ebastine 1\% w/v ocular formulation) + Ovalbumin

Mild epithelium damage and, there was less eosinophil infiltration than in conjunctiva of guinea pigs treated with ovalbumin alone (40x) Fig. 7: Histopathlogical Photomicrographs of the conjunctival tissues in Ovalbumin induced Allergic conjunctivitis in guinea pigs treated with (a) Saline (b) Saline + Ovalbumin (c) Test formulation (Ebastine 1\% w/v ocular formulation) + Ovalbumin.

In future, pharmacokinetic study and ocular tissue distribution study need to be performed to precisely define ADME pattern of said formulation after ocular application.

\section{ACKNOWLEDGEMENT}

The authors are also grateful to Parul University and ITM School of Pharmacy, Gujarat Technological University for providing research related facilities. We want to thanks Government Poultry House, Vadodara for providing fertilized eggs for CAM assay. We would like to thank Dr. Prachi Karia, Assistant Professor for assisting in CAM assay. We would like to thank Mr. Sameer Mehetre, Senior Manager, Drug Discovery (Pharmacology), Sun Pharma Advanced Research Company Ltd (SPARC), Vadodara for his kind help in data analysis.

\section{REFERENCES}

1. Mashige KP. Ocular allergy. Health SA gesondheid. 2017; 22(1):112-122.

2. Sánchez MC, Fernández PB, Matheu V, Navarro A, Ibáñez MD, Dávila I, et al. Allergic conjunctivitis. Journal of investigative allergology and clinical immunology. 2011; 21(2 Suppl):1-9.

3. Rico S, Antonijoan RM, Barbanoj MJ. Ebastine in the light of CONGA recommendations for the development of thirdgeneration antihistamines. Journal of asthma and allergy. 2009; 2:73.

4. Chowdhury B. Allergic conjunctivitis-A review. Dehli ophthalmogical society times. 2013; 19:41-7.

5. Proud D, Sweet J, Stein P, Settipane RA, Kagey SA, Friedlaender $\mathrm{MH}$, et al. Inflammatory mediator release on conjunctival provocation of allergic subjects with allergen. Journal of allergy and clinical immunology.1990; 85: 896-905.

6. Mishra GP, Tamboli V, Jwala J, K Mitra A. Recent patents and emerging therapeutics in the treatment of allergic conjunctivitis. Recent patents on inflammation \& allergy drug discovery. 2011; 5 (1):26-36.

7. Abelson MB, Chapin MJ, Gomes P, Minno G, Nice J, inventors; Aciex Therapeutics Inc, assignee. Ophthalmic formulations of cetirizine and methods of use. United States patent US 8,569,273. 2013 Oct 29.

8. Chang CM, Farnes EQ, Olejnik O, Chang JN, inventors Allergan Inc, assignee. Ophthalmic compositions containing loratadine. United States patent US 6, 635,654. 2003 Oct 21

9. Mehetre J, Vimal K, Mehta T, Gohel M, Surti N. Rationalized Approach for Formulation and Optimization of Ebastine Microemulsion Using Design Expert for Solubility Enhancement. Journal of drug delivery and therapeutics. 2019; 9(3-s):386-397.

10. Bagley DM, Rizvi PY, Kong BM, Salvatore JD. Factors affecting use of hen's egg chorioallantoic membrane as a model for predicting eye irritation potential: I. Journal of toxicology. Cutaneous and ocular toxicology. 1991; 10:95-104.

11. Bagley DM, Rizvi PY, Kong BM, Salvatore JD. Evaluation of the vascular components of the chorioallantoic membrane assay as a model for eye irritation potential: II. Journal of toxicology. Cutaneous and ocular toxicology. 1991; (10):105113.

12. Deepthi S, Jose J. Novel hydrogel-based ocular drug delivery system for the treatment of conjunctivitis. International ophthalmology. 2018; 19:1-2.

13. Bar-ilan AM. The Guinea Pig Blinking Test: A Comparison with Human Responses. Journal of ocular pharmacology and therapeutics. 1997; 13(3):207-212.

14. Alany RG, Rades T, Nicoll J, Tucker IG, Davies NM. W/O microemulsions for ocular delivery: Evaluation of ocular irritation and precorneal retention. Journal of controlled release. 2006; 111(1-2):145-52.

15. Satyam SM, Adiga S, Chogtu B, Bairy KL, Pirasanthan R, Vaishnav RL. Effect of fucithalmic and sofinox eye drops on experimental allergic conjunctivitis in rats. International Journal of pharmacy and pharmaceutical sciences. 2014; 6(11):458-60. 
J Mehetre et al. / Ocular Tolerability and Efficacy of Ebastine Colloidal Formulation in Allergic

16. Groneberg DA, Bielory L, Fischer A, Bonini S, Wahn U. Animal models of allergic and inflammatory conjunctivitis. Allergy. 2003; 58(11):1101-13.

17. Yanni JM, Stephens DJ, Parnell DW, Spellman JM. Preclinical efficacy of emedastine, a potent, selective histamine H1 antagonist for topical ocular use. Journal of ocular pharmacology. 1994; 10:665-675.

18. Nakazawa Y, Oka M, Takehana M. Model for studying antiallergic drugs for allergic conjunctivitis in animals. Open medicine. 2017; 12(1):231-238.

19. Minami K, Chiaki K. A chronic model for evaluating the itching associated with allergic conjunctivitis in rats. International immunopharmacology.2004; 4:101-8.

20. Shoji J, Inada N, Takaura N, Sawa M. Histological study of allergic conjunctivitis. report 1 . Study on the adhesion molecules to allergic conjunctivitis. Journal of Japanese ophthalmological society. 1995; (99)2:129-134.

21. Shoji J, Inada N, Takaura N, Sawa M. Histological study of allergic conjunctivitis report 2. Time course of allergic conjunctival inflammation. Nihon ganka kiyo. 1995; 46(10):1015-1020.

22. Kyei S, Koffuor GA, Ramkissoon P, Abokyi S, Owusu-Afriyie $\mathrm{O}$, Wiredu EA. Possible mechanism of action of the antiallergic effect of an aqueous extract of Heliotropium indicum L. in ovalbumin-induced allergic conjunctivitis. Journal of allergy. 2015; 1-7.
23. Bonini S. Allergic conjunctivitis: the forgotten disease. Chemical immunology and allergy. 2006; 91:110-120.

24. MihaI B. Current therapy of allergic conjunctivitis. Current therapeutic research.1997; 58 (11):1-11.

25. Katelaris $\mathrm{CH}$. Allergic rhinoconjunctivitis: an overview. Acta ophthalmol scand. 2000; 230:66-68.

26. Kamei C, Izushi K, Tasaka K. Inhibitory effect of levocabastine on experimental allergic conjunctivitis in guinea pigs. Journal of pharmacobio-dynamics. 1991; 14(4) $67-73$.

27. Kamei C, Sugimoto Y, Nakamura S, Zhong C. Effect of (Z)11- [3-(dimethylamino) propylidene]-6, 11-dihydrodibenz [b, e] oxepin-2-acetic acid hydrochloride on experimental allergic conjunctivitis and rhinitis in rats and guinea pigs. Arzneimittel-forschung/drug research.1995; 45(100):5-8.

28. Palmares J, Delgado L, Cidade M, Quadrado MJ, Filipe HP. Allergic conjunctivitis: a national cross-sectional study of clinical characteristics and quality of life. European journal of ophthalmology. 2010; 20(2):257-264.

29. Sánchez MC, Fernández Parra B, Matheu V, Navarro A, Ibáñez MD, Dávila I, Dordal MT, Lluch Bernal M, Rondón C, Montoro J, Antón E. Allergic conjunctivitis. Journal of investigational allergology and clinical immunology. 2011; 21(2 Suppl):1-9.

HOW TO CITE THIS ARTICLE: Mehetre J, Kumar V, Mehta T, Gohel M, Surti N. Ocular Tolerability and Efficacy of Ebastine Colloidal Formulation in Allergic Conjunctivitis. Int. J. Pharm. Sci. Drug Res. 2019; 11(4): 129136. DOI: 10.25004/IJPSDR.2019.110405 